\title{
Does egg deposition by herbivorous pine sawflies affect transcription of sesquiterpene synthases in pine?
}

\author{
Diana Köpke • Roland Schröder · Hanna M. Fischer • \\ Jonathan Gershenzon · Monika Hilker · Axel Schmidt
}

Received: 28 January 2008 / Accepted: 29 April 2008 / Published online: 21 May 2008

(C) The Author(s) 2008

\begin{abstract}
Scots pine (Pinus sylvestris; Pinaceae, Pinales) is known to defend against egg deposition by herbivorous sawflies by changing its terpenoid volatile blend. The oviposition-induced pine odor attracts egg parasitoids that kill the sawfly eggs. Here, we investigated whether sawfly egg deposition activates genes encoding pine terpene synthases by extracting mRNA from oviposition-induced $P$. sylvestris. Three new sesquiterpene synthases, PSTPS 1, PSTPS 2, and PSTPS 3, were isolated that were shown on heterologous expression in Escherichia coli to produce (E)- $\beta$-caryophyllene and $\alpha$-humulene (PSTPS 1), 1(10),5-germacradiene-4ol (PSTPS 2), and longifolene and $\alpha$-longipinene (PSTPS 3) as their principal products. Quantitative RT-PCR analyses revealed that transcript levels of PSTPS 1 and PSTPS 2 were significantly higher in oviposition-induced twigs that were
\end{abstract}

Accession Number: The PsTPS 1, PsTPS 2 and PsTPS 3 sequences were deposited in GenBank, accession number EF679330, EF679331, and EF679332, respectively.

Electronic supplementary material The online version of this article (doi:10.1007/s00425-008-0747-8) contains supplementary material, which is available to authorized users.

D. Köpke · H. M. Fischer · J. Gershenzon · A. Schmidt

Max Planck Institute for Chemical Ecology,

Beutenberg Campus, Hans-Knöll-Str. 8, 07745 Jena, Germany

e-mail: aschmidt@ice.mpg.de

D. Köpke · R. Schröder · H. M. Fischer · M. Hilker $(\square)$

Institute of Biology, Freie Universität Berlin,

Haderslebener Str. 9, 12163 Berlin, Germany

e-mail: hilker@zedat.fu-berlin.de

R. Schröder

Department of Zoology, University of Hawaii,

2538 McCarthy Mall, Edmondson Hall 259,

Honolulu, HI 96822, USA attractive to the parasitoids than in non-attractive, artificially damaged twigs. Thus, our results demonstrate a specific transcription response to egg deposition, distinct from that caused by artificial wounding. Transcripts of PSTPS 3 did not change in response to egg deposition. The transcript levels of PSTPS 1, PSTPS 2, and PSTPS 3 were also determined in relation to time after egg deposition, since pine odor is attractive to the parasitoid only $72 \mathrm{~h}$ after egg deposition. Transcription rates of PSTPS 1 and PSTPS 2 were significantly enhanced only $72 \mathrm{~h}$ after egg deposition, thus matching the timing of odor attractiveness, while for PSTPS 3 , enhanced transcription was not detected at any time period studied after egg deposition. The ecological significance of the oviposition-induced increase of sesquiterpene synthase transcripts is discussed.

Keywords Conifers - Diprion pini $\cdot$ Egg deposition · Induced defense $\cdot$ Pinus $\cdot$ Terpene synthase

$\begin{array}{ll}\text { Abbreviation } \\ \text { TPS } & \text { Terpene synthases } \\ \text { FPP } & \text { Farnesyl diphosphate } \\ \text { GPP } & \text { Geranyl diphosphate } \\ \text { GGPP } & \text { Geranylgeranyl diphosphate }\end{array}$

\section{Introduction}

Numerous plant species were shown to change the composition of their odor in response to herbivore feeding (Karban and Baldwin 1997; Walling 2000). This attack-induced change of the plant volatile pattern is known to attract natural enemies of herbivorous arthropods, including predators and parasitoids (Dicke and van Loon 2000; Gatehouse 2002). Terpenoids are major components of plant volatile 
blends and play a predominant role in the attraction of enemies of the herbivores (Van Poecke and Dicke 2004).

Change in plant odor is induced not only by herbivore feeding, but also by insect egg deposition. In several plant species, oviposition-induced volatiles (among them monoand sesquiterpenes) were shown to attract egg parasitoids (Hilker et al. 2002a; Hilker and Meiners 2002; Colazza et al. 2004; Mumm and Hilker 2006). These compounds are released locally from the site of egg deposition and also systemically from adjacent egg-free plant parts (e.g., Hilker and Meiners 2006; Hilker et al. 2002b). Such an indirect defensive plant strategy is considered an "early herbivore alert", since it acts even prior to the onset of larval feeding damage (Hilker and Meiners 2002, 2006).

The change of the pattern of terpenoids released by a plant under herbivore attack may be due to (1) damage of cells releasing stored terpenoids (Röse et al. 1996; Röse and Tumlinson 2004), or (2) changes in the de novo synthesis of terpenoids that are released immediately after production (Paré and Tumlinson 1997). This de novo synthesis in turn has often been ascribed to the activation of genes encoding terpene synthases (e.g., Bohlmann et al. 1999; McKay et al. 2003; Arimura et al. 2004; Kappers et al. 2005; Miller et al. 2005; Byun-McKay et al. 2006; Schnee et al. 2006).

Like feeding-induced terpenes, oviposition-induced plant terpenoid volatiles can also be expected to be a result of activation of terpene synthase genes based on the following lines of evidence: (1) while cell damage accompanying egg deposition may allow release of stored terpenes, the emission of attractive volatiles from systemically (nondamaged) oviposition-induced plant parts cannot be due to release from damaged cells, but are rather due to de novo synthesis (Meiners and Hilker 2000; Hilker et al. 2002b). (2) Egg deposition by Pieris brassicae on Arabidopsis thaliana does not cause any obvious leaf damage, but nevertheless induces a wide range of plant genes, including two terpene synthases (Little et al. 2007). It is not known whether A. thaliana changes its volatiles in response to insect egg deposition.

Thus, no study is available so far explaining how insect egg deposition affects the release of volatiles in those plant species that attract egg parasitoids by oviposition-induced odor. Is such a change of plant volatiles regulated on the molecular level by oviposition-induced enhanced transcription of genes encoding enzymes involved in biosynthesis of the relevant volatiles? We addressed this question by studying Pinus sylvestris (Scots pine), a species that changes its odor locally and systemically in response to egg deposition by the pine sawfly Diprion pini. An egg parasitoid, the eulophid wasp Chrysonotomyia ruforum which may significantly limit sawfly populations, is attracted by the oviposition-induced odor of Scots pine (Eichhorn and PschornWalcher 1976; Hilker et al. 2002b, 2005). The sawfly female slits a needle longitudinally with her sclerotized ovipositor valves and lays eggs into the slit. Mimicking this ovipositional wounding artificially with a scalpel does not result in release of volatiles attracting the egg parasitoid (Hilker et al. 2002b). These studies showed that pine responds specifically to sawfly egg deposition.

The volatile blend released from attractive, ovipositioninduced $P$. sylvestris differs only slightly from the one released by a non-attractive (artificially wounded) control. Non-attractive pine twigs released the same terpenoid compounds. However, the oviposition-induced pine releases significantly larger quantities of the sesquiterpene $(E)-\beta$ farnesene (Mumm et al. 2003). This sesquiterpene was shown to attract the parasitoid $C$. ruforum only when offered in combination with volatiles from non-attractive control $P$. sylvestris (Mumm and Hilker 2005), indicating that the ratio of $(E)$ - $\beta$-farnesene and other volatile terpenoids within a complex blend is responsible for parasitoid attraction. The specific role of $(E)-\beta$-farnesene for attraction of parasitoids is further supported by the following findings: (a) jasmonic acid (JA) treated pine twigs release enhanced quantities of $(E)$ - $\beta$-farnesene, and the odor of these JA-treated pine twigs is attractive to the parasitoids (Mumm et al. 2003); (b) the egg parasitoid shows a very clear-cut electrophysiological antennal response to $(E)$ - $\beta$-farnesene, $(E)$ - $\beta$-caryophyllene, and $\alpha$-humulene (own unpublished data).

In this study, we aimed to elucidate whether egg deposition by $D$. pini affects transcription of sesquiterpene synthases. Since no sesquiterpene synthase sequence was known from $P$. sylvestris, we first identified and functionally characterized three sesquiterpene synthases in this species. Further, we compared the transcript levels of these sesquiterpene synthases in oviposition-induced pine twigs to those in artificially wounded ones to elucidate whether the transcriptional response was specific for oviposition. In previous studies (Mumm et al. 2003), odor from pine twigs $72 \mathrm{~h}$ after sawfly egg deposition was shown to attract the egg parasitoids, but it is unknown whether attractive odor is also released after a shorter or longer time. Therefore, we studied the parasitoid's response to pine odor at different times after sawfly egg deposition. Parallel to these behavioral studies, we also studied how transcription rates of the three sesquiterpene synthases change over time after egg deposition.

\section{Materials and methods}

Study organisms

\section{Plants}

Both for the molecular studies and the behavioral bioassays with parasitoids, plant material was taken from $P$. sylvestris 
trees growing in forests near Berlin, Germany. In the laboratory, cut pine twigs were subjected to standardized and controlled conditions during treatment $\left(25^{\circ} \mathrm{C}, 18: 6 \mathrm{~h}\right.$ light/ dark cycle, and approx. 2,000 lx). Twigs kept at these standardized conditions have been proven to provide reproducible results when studying the parasitoid's response to oviposition-induced pine odor (Hilker et al. 2002b; Mumm et al. 2005). The inducibility of pine twigs by sawfly egg deposition was checked during the time when samples were taken for molecular studies. The twigs were considered inducible and used for molecular studies when the egg parasitoid $C$. ruforum responded positively to odor from samples $72 \mathrm{~h}$ after sawfly egg deposition. Branches of $P$. sylvestris used for analyses were cut from the middle part of 10- to 15-year-old trees and also from the lower part of 35- to 45-year-old trees. The lower part of a branch was cleaned, sterilized according to Moore and Clark (1968), and placed into water for treatment (see below). Plant material was taken in different seasons in 2004-2007.

\section{Insects}

The sawfly D. pini (Hymenoptera, Diprionidae) was reared in the laboratory on pine branches as described by Bombosch and Ramakers (1976) and Eichhorn and Pschorn-Walcher (1976) at $25 \pm 1{ }^{\circ} \mathrm{C}, 65 \% \mathrm{RH}$, and 18:6 h light/dark cycles. The egg parasitoid C. ruforum (Hymenoptera, Eulophidae) was collected in the field in southern Finland. Pine needles with parasitized host eggs were kept in Petri dishes at $5^{\circ} \mathrm{C}$. To initiate parasitoid emergence from host eggs, parasitized eggs were transferred to a climate chamber with $25 \pm 1{ }^{\circ} \mathrm{C}, 65 \% \mathrm{RH}$, and 18:6 h light/dark cycles. Emerging adults were collected daily and transferred to $10 \pm 1{ }^{\circ} \mathrm{C}$, $65 \% \mathrm{RH}$, and $16: 8 \mathrm{~h} \mathrm{light/dark}$ cycles until they were used for bioassays.

\section{Plant treatments}

\section{General}

All types of twigs (egg-laden, artificially wounded, and untreated) were always cut from the same larger branch to minimize possible intra-tree-variation in terpenoid metabolism. For each experiment, pine twigs with 80-100 needles were cut, placed into a glass cylinder covered by a gauze lid, and supplied with water. An oviposition-induced twig is referred to here as test twig. For controls, two types of twigs were used: (a) a twig with an artificial wounding mimicking the ovipositional wounding, and (b) an untreated twig. Test and control twigs were always cut at the same time and kept at the same conditions. To obtain needle material for the molecular analyses, needles from control twigs were always removed at the same time points as needles from the respective test twigs and subjected to further analyses (see below).

\section{Pine twig treatments}

To obtain egg-laden pine twigs, three female and three male $D$. pini were added to a glass cylinder with a twig for a period of $16 \mathrm{~h}$. During this time, the sawflies mated, and eggs were laid. When insects were removed from the cylinder, this was designated time zero $(\mathrm{t} 0)$. The egg-laden twig (with about eight to ten needles carrying an egg mass) was then kept for 48,72 , or $96 \mathrm{~h}$ at the conditions described above. After these time periods, needles without eggs were removed from these twigs and subjected to further analyses. To obtain artificially wound-induced pine twigs, eight to ten needles of a pine twig were longitudinally slit at time point $t 0$. The depth and length of the slit mimicked the wounding made by an ovipositing female $D$. pini with her ovipositor valves. The unwounded needles were removed from the wound-induced twigs 48,72 , or $96 \mathrm{~h}$ after treatment and used for further analyses. To obtain a branch-specific untreated twig control, needles from untreated control twigs were removed at the same time points as from the respective oviposition- or wound-induced twigs and subjected to further analyses. The time points when samples were collected for the molecular analyses reflected the times when behavioral studies were conducted.

\section{Behavioral studies}

A four-arm airflow olfactometer (Pettersson 1970; Vet et al. 1983) was used to test whether the egg parasitoid $C$. ruforum is attracted to odor of egg-laden pine twigs with an induction time other than $72 \mathrm{~h}$ (Hilker et al. 2002b). Airflows of 155 $\mathrm{ml} \mathrm{min}{ }^{-1}$ were allowed to enter a walking arena from four sides, thus establishing four distinct odor fields. One field was supplied with odor from an oviposition-induced pine twig, while the other fields were supplied with charcoalfiltered, humidified air (for further details see Hilker et al. 2002b). The parasitoid's response was tested to odor from twigs with 48, 72, and 96 induction time. Even though the parasitoid's response to odor from induced twigs $72 \mathrm{~h}$ after oviposition was known to be positive, this bioassay was included as positive control. When starting the bioassay, a single parasitoid female was introduced into the arena. The time the parasitoid spent walking in each of the four odor fields was recorded during an observation period of $600 \mathrm{~s}$ using a software program, The Observer 3.0 (Noldus, Wageningen, The Netherlands). Only data from active parasitoids walking at least $300 \mathrm{~s}$ of the observation period were used for statistical analysis. The number of parasitoids used per treatment was 34-37 (Table 1). The number of odor sources (twigs) tested was 6-9 per bioassay (Table 1). Data 
Table 1 Ecological relevance of induction time

\begin{tabular}{|c|c|c|c|c|c|c|c|}
\hline \multirow[t]{2}{*}{ Induction time $(\mathrm{h})^{*}$} & \multicolumn{4}{|c|}{ Duration of walking (s) } & \multirow[t]{2}{*}{$N$ parasitoid } & \multirow[t]{2}{*}{$N$ twig } & \multirow[t]{2}{*}{$P$} \\
\hline & Test field & Control 1 & Control 2 & Control 3 & & & \\
\hline 48 & $163(84-262)$ & $107(8-156)$ & $79(37-147)$ & $105(44-164)$ & 34 & 7 & 0.214 \\
\hline 72 & $174^{\mathrm{a}}(116-259)$ & $91^{\mathrm{ab}}(27-199)$ & $65^{\mathrm{b}}(29-138)$ & $117^{\mathrm{ab}}(41-170)$ & 37 & 6 & 0.009 \\
\hline 96 & $121(42-182)$ & $99(35-156)$ & $133(68-245)$ & $129(67-177)$ & 37 & 9 & 0.447 \\
\hline
\end{tabular}

${ }^{*}$ Response of female egg parasitoids of $C$. ruforum to volatiles released from pine twigs carrying eggs for 48,72 , or $96 \mathrm{~h}$ (=induction time). Odor from these egg-laden twigs was offered in the test field of a four-arm-olfactometer with three control fields (clockwise arranged) supplied with clean air. Medians and interquartiles (parenthesis) for the time the parasitoid female spent walking over an observation period of $600 \mathrm{~s}$ are given for each field. The $P$ value was evaluated by a Friedman ANOVA. Different letters indicate significant $(P<0.05)$ differences evaluated by Wilcoxon-Wilcox tests

were analyzed by Friedman ANOVA by comparing walking times within each of the four odor fields. Wilcoxon-Wilcox tests were used for post-hoc comparison (Köhler et al. 1995). The analysis was performed using StatSoft, Version 1999, STATISTIKA for Windows (Tulsa, OK, USA).

\section{Chemicals}

All chemicals and solvents were of analytical grade and were obtained from Merck, Serva, or Sigma. The substrates geranyl diphosphate (GPP), farnesyl diphosphate (FPP), and geranylgeranyl diphosphate (GGPP) were from Echelon Res. Lab. Inc. (Salt Lake City, UT, USA).

RNA isolation and cDNA synthesis

Needle tissue from treated $P$. sylvestris twigs (see above) harvested 48,72 , or $96 \mathrm{~h}$ after oviposition or artificial wounding treatments or from respective control twigs was ground in liquid nitrogen with a sterilized mortar and pestle. To isolate RNA, the Invisorb Spin RNA Mini Kit (Invitek, Berlin, Germany) protocol was followed. Approximately, $100 \mathrm{mg}$ of plant tissue was used per extraction. The RNA was eluted with $30 \mu \mathrm{l}$ of RNAse free deionized water. For qRT-PCR, an additional DNase treatment was added using the RNase-Free DNase Kit (Qiagen, Hilden, Germany). Total RNA was checked for integrity and purity by spectrophotometer and tested additionally with RNA Nano Chips (Regent kit guide, RNA 6000 Nano assay, Agilent Technologies) by using a Bioanalyzer Agilent 2100 (Agilent Technologies). The synthesis of single stranded cDNA was carried out using Superscript III reverse transcriptase (Invitrogen), 0.6-3 $\mu \mathrm{g}$ RNA and oligo (dT) ${ }_{20}$ primers (Invitrogen) according to the manufacturer's instructions. For qRT-PCR analysis, identical amounts of total RNA were used for reverse transcription.

Isolation of pine terpene synthase cDNA clones

Conserved regions of gymnosperm sesquiterpene synthases sequences from the following species (listed with accession numbers) were used to design degenerate primers: Picea abies (AAC05727, AAK39129, AAS47695) and Abies grandis (AAK83561, AAC06728). Using these primers, cDNA fragments were amplified from pine twigs $72 \mathrm{~h}$ after egg deposition by PCR under the following conditions: 0.2 $\mu \mathrm{l}$ Taq DNA Polymerase (5 U/ $\mu \mathrm{l}), 2.5 \mu \mathrm{l} 10 \times$ PCR-buffer for Taq Polymerase, $1 \mu \mathrm{l}$ dNTPs $(10 \mathrm{mM}), 1 \mu \mathrm{l}$ primer 1 and 2 (10 pmol $/ \mu \mathrm{l}$; see Supplemental data, Table S1), 0.2-3 $\mu \mathrm{l}$ cDNA, and $\mathrm{H}_{2} \mathrm{O}$ (added up to $25 \mu \mathrm{l}$ ). The PCR was conducted with an initial denaturation at $94^{\circ} \mathrm{C}$ for $3 \mathrm{~min}, 40$ cycles of denaturation at $94^{\circ} \mathrm{C}$ for $40 \mathrm{~s}$, annealing at $55^{\circ} \mathrm{C}$ for $40 \mathrm{~s}$, extension at $72^{\circ} \mathrm{C}$ for $70 \mathrm{~s}$, and a final step at $72^{\circ} \mathrm{C}$ for 5 min. For ligation and cloning of PCR fragments, the TOPO TA cloning ${ }^{\mathrm{TM}}$ kit for sequencing was used (Invitrogen). To generate the full-length coding cDNA sequence of the corresponding cDNA fragments, the BD SMART ${ }^{\mathrm{TM}}$ RACE cDNA Amplification Kit (Clontech) was used according to the manufacturer's instructions. The resulting cDNA amplicons were cloned into vector pCR 4-TOPO (Invitrogen) and sequenced using an ABI 3100 automatic sequencer (Applied Biosystems).

Functional expression of PSTPS 1, PSTPS 2, and PsTPS 3

The complete open reading frames of the full length cDNA of PSTPS 1, PSTPS 2, and PSTPS 3 clones and the signal peptide truncated version of PSTPS 2 were used for functional expression. PCRs were performed with primers (see Supplemental data Table S1) using the Expand High Fidelity Plus PCR System (Roche) as directed by the manufacturer. The amplification products were cloned into the pET$100 \mathrm{D} \mathrm{TOPO}^{\mathrm{TM}}$ expression vector (Invitrogen). The expression vector was transformed into the E. coli strain Top $10 \mathrm{~F}^{\prime}$ and its sequence verified. Mutation-free plasmids were transformed into the BL21 (DH3) pLysS strain of E. coli (Invitrogen).

For bacterial expression, a starter culture $(10 \mathrm{ml}$ LuriaBertani medium with $35 \mu \mathrm{g} / \mathrm{ml}$ chloramphenicol and 100 $\mu \mathrm{g} / \mathrm{ml}$ of carbenicillin) was grown for 3 days at $18^{\circ} \mathrm{C} ; 5 \mathrm{ml}$ of starter culture in $100 \mathrm{ml} \mathrm{LB}$ medium (with $35 \mu \mathrm{g} / \mathrm{ml}$ of 
chloramphenicol and $100 \mu \mathrm{g} / \mathrm{ml}$ carbenicillin) was induced with $2 \mathrm{mM}$ isopropyl- $\beta$-galactoside (IPTG) at an OD $=0.6$ and kept at $18^{\circ} \mathrm{C}$ for at least $15 \mathrm{~h}$. The cells were centrifuged for $20 \mathrm{~min}$ at $9,000 \mathrm{~g}$. The pellets were resuspended in $3 \mathrm{ml}$ of extraction buffer (Martin et al. 2004) and disrupted by sonication (Bandelin Sonopuls HD 2070, Berlin, Germany) for $4 \mathrm{~min}$, cycle 2 , power $60 \%$. After freezing (10 min at $-20^{\circ} \mathrm{C}, 10 \mathrm{~min}$ at $\left.-80^{\circ} \mathrm{C}\right)$, the cell fragments were collected by centrifugation.

The supernatant containing the total bacterial crude protein extract was assayed. Each assay was performed in a 1 ml volume with $69.9 \mu \mathrm{M}$ FPP, overlaid with $1 \mathrm{ml}$ pentane, and incubated at $30^{\circ} \mathrm{C}$. For control assays, substrate concentrations of $99.5 \mu \mathrm{M}$ GPP and 37.0 $\mu \mathrm{M}$ GGPP were used. One hour after pentane addition, the assay was stopped by vigorous vortexing with the pentane overlay for $30 \mathrm{~s}$ and separation of the aqueous and organic fractions by centrifugation at $2,500 \mathrm{~g}$ for $2 \mathrm{~min}$. The pentane fraction was removed, and the residue was overlaid again with $1 \mathrm{ml}$ pentane. In total, three consecutive pentane extractions were conducted. Finally, the pentane fractions were combined, dried over a silica/ $\mathrm{MgSO}_{4}$ column, and evaporated to 50$100 \mu \mathrm{l}$. These samples were subjected to GC-MS analyses (see below, product identification).

Enzyme concentrations were measured according to Bradford (1976) by using the BioRad reagent with bovine serum albumin (BSA) as standard. The protein concentration used in each assay was adjusted prior to a range of $0.5-2.5 \mu \mathrm{g} / \mathrm{ml}$.

Sesquiterpene extraction from needle tissue

To investigate whether the expression levels of the sesquiterpene synthases in differently treated pine twigs were reflected by different amounts of the major products of these synthases, we analyzed (a) oviposition-induced pine twigs $72 \mathrm{~h}$ after egg deposition and (b) artificially wounded pine twigs $72 \mathrm{~h}$ after treatment for their sesquiterpene contents. For terpene extraction, $200 \mathrm{mg}$ ground needles (see above, RNA isolation and cDNA synthesis) were used. The extraction procedure was based on a method described by Martin et al. (2002). All steps were carried out in $2 \mathrm{ml}$ vials tightly closed with a teflon-coated screw cap (Hewlett-Packard, Palo Alto, CA, USA). The needle samples were submerged into $1.0 \mathrm{ml}$ of tert-butyl methyl ether containing $150 \mu \mathrm{g} / \mathrm{ml}$ isobutylbenzene as internal standard and extracted $14 \mathrm{~h}$ overnight with constant shaking at room temperature. The ethereal supernatant was transferred to a fresh vial and washed with $0.3 \mathrm{ml}$ of $0.1 \mathrm{M}\left(\mathrm{NH}_{4}\right)_{2} \mathrm{CO}_{3}(\mathrm{pH} 8.0)$. This sample was filtered through a Pasteur pipette column filled with $0.3 \mathrm{~g}$ of silica gel (Sigma $60 \AA$ ) overlaid with $0.2 \mathrm{~g}$ of anhydrous $\mathrm{MgSO}_{4}$. The column was washed with $1 \mathrm{ml}$ of diethyl ether. The eluate was evaporated to an approximate volume of $100 \mu \mathrm{l}$ and used for further GC-MS analyses of terpenoids (see below, product identification).

\section{Product identification}

Products of sesquiterpene synthase assays and extracts of pine needles were analyzed on a GC system (Agilent Hewlett-Packard 6890, Agilent Technologies) coupled to a Network Mass Selective Detector (Agilent Hewlett-Packard 5973, Agilent Technologies). For analyses, $1 \mu$ concentrated pentane phase (assays) or ether phase (needle extract) was injected at an injector temperature of $220^{\circ} \mathrm{C}$ on a HP-5 capillary column $(30 \mathrm{~m} \times 0.25 \mathrm{~mm}$ with a $0.25 \mu \mathrm{m}$ phase coating; Agilent Technologies). The temperature program started with $40^{\circ} \mathrm{C}$ for $2 \mathrm{~min}$, raised to $210^{\circ} \mathrm{C}\left(5^{\circ} \mathrm{C} \mathrm{min}{ }^{-1}\right)$, and raised further to $300^{\circ} \mathrm{C}\left(60^{\circ} \mathrm{C} \mathrm{min}^{-1}, 2 \mathrm{~min}\right.$ hold; helium flow: $2 \mathrm{ml} \mathrm{min}^{-1}$ ). For identification of compounds, the MS detector was operated using the total ion mode at a temperature of $230^{\circ} \mathrm{C}$. The products were identified by comparing mass spectra and retention times with those in the literature and in the Wiley 275.L or NIST 98.1 MS libraries. The identity of $(E)$ - $\beta$-caryophyllene, $\alpha$-humulene, longipinene, and longifolene was further verified by comparison with authentic standards.

Those sesquiterpenes that were the major products of the sesquiterpene synthases were quantified in pine needle extracts with $150 \mu \mathrm{g} / \mathrm{ml}$ isobutylbenzene as internal standard (compare above). Mean $\pm \mathrm{SE}$ of the relative quantities of these compounds were calculated from three independent biological pine needle samples of each treatment with each biological sample analyzed three times.

\section{QRT-PCR}

Real time quantification of gene transcription was performed using SYBR green QPCR Master Mix from Stratagene (La Jolla, CA, USA) in order to address the following questions: (a) do transcript levels of PSTPS 1-3 differ between oviposition-induced samples and artificially wounded ones?; (b) how do transcript levels of these sequences change over time after treatment?

QRT-PCRs were performed as described in the operator's manual using a Stratagene MX3000P ${ }^{\mathrm{TM}}$. Gene-specific PCR primers were designed (see Supplemental data Table S1) using criteria including predicted melting temperature of at least $58^{\circ} \mathrm{C}$, primer length of $22-24$ nucleotides, guanosine-cytosine content of at least $48 \%$, and an amplicon length of 120-150 bp. Primer specificity was confirmed by melting curve analysis, by an efficiency of product amplification of $1.0 \pm 0.1$, and by sequence verification of at least eight cloned PCR amplicons for each gene. Reactions with water instead of cDNA template were run with each primer pair as control. The standard thermal profile of 
$95^{\circ} \mathrm{C}$ for $10 \mathrm{~min}$, then $60 \mathrm{cycles}$ of $95^{\circ} \mathrm{C}$ for $30 \mathrm{~s}, 53^{\circ} \mathrm{C}$ for $30 \mathrm{~s}$ and $72^{\circ} \mathrm{C}$ for $30 \mathrm{~s}$ was used. The fluorescence signal was captured at the end of each cycle, and a melting curve analysis was performed from the annealing temperature to $95^{\circ} \mathrm{C}$ with data capture every $0.2^{\circ} \mathrm{C}$ during a $1 \mathrm{~s}$ hold.

The quantity of each transcript is the average of four (48 h), five (72 h), and three (96 h) independent biological replicates, each of which is represented by at least three technical replicates. All amplification plots were analyzed with the MX3000 $\mathrm{P}^{\mathrm{TM}}$ software to obtain threshold cycle $\left(C_{\mathrm{t}}\right)$ values. Transcript abundance was normalized to the transcript abundance of ubiquitin (GenBank accession number EF681766). Relative transcript values were obtained by calibration first against the transcript abundance of the respective untreated twig control, and, second, against the transcript abundance of the artificial wounding control $72 \mathrm{~h}$ after treatment.

A two-way ANOVA was performed on qRT-PCR raw data to test the significance of differences in changes of PSTPS 1, PSTPS 2, and PSTPS 3 transcript levels in course of time (independent samples; between-subject factor time) and due to treatment (dependent, paired samples; withinsubject factor treatment). Also the combined effect of time $\times$ treatment was statistically tested. Normal distribution of qRT-PCR raw data was found for PSTPS 1 and PSTPS 3. PSTPS 2 data were arctan-transformed prior to ANOVA (Sokal and Rohlf 1995). All analyses were performed using StatSoft, Version 1999, STATISTICA for Windows (Tulsa, OK, USA) (see Supplemental data Table S2).

Sequence and phylogenetic analyses

DNASTAR Lasergene program version 7.0 (Meg Align ${ }^{\mathrm{TM}}$ ) was used to align and to calculate the deduced amino acid sequences of each full-length $P$. sylvestris cDNA and of known sequences from gymno- and angiosperms. The amino acid alignment was assembled by use of ClustalW (gonnet 250 matrix, gap penalty: 10.00, gap length penalty: 0.20 , delay divergent sequences: $30 \%$, gap length 0.10 , DNA transition weight 0.5 ). The same software was used to visualize the phylogenetic tree.

\section{Results}

Timing of egg parasitoid attraction to $P$. sylvestris foliage

Behavioral bioassays were conducted to study the parasitoid's response to pine odor after different periods of time after sawfly egg deposition. The parasitic wasps showed a significantly positive response to odor from pine twigs laden with pine sawfly eggs for $72 \mathrm{~h}$, thus confirming previous results (Hilker et al. 2002b, 2005; Mumm et al. 2003).
However, at shorter (48 h) or longer (96 h) times after oviposition, the odor of pine twigs did not attract the parasitoids (Table 1).

Cloning of sesquiterpene synthases from P. sylvestris

By the use of degenerate primers corresponding to conserved regions of known conifer sesquiterpene synthases and $5^{\prime}$-and $3^{\prime}$-RACE-PCR cloning strategies, three different cDNA clones containing open reading frames (ORFs) of terpene synthases were obtained from RNA isolated from oviposition-induced $P$. sylvestris twigs $(72 \mathrm{~h}$ after egg deposition). The clones were designated PSTPS 1, 1,728 bp encoding an ORF of 576 amino acids; PsTPS 2, 1,878 bp encoding an ORF of 626 amino acids, and PSTPS 3, 1,743 bp encoding an ORF of 581 amino acids. The deduced amino acid sequences of all three clones, when compared with other conifer terpene synthases, showed the two typical aspartate-rich DDxxD motifs which are involved in coordinating the bivalent metal ion for substrate binding (Bohlmann et al. 1999). In PSTPS 1 and PSTPS 2, an $\mathrm{RR}(\mathrm{x} 8) \mathrm{W}$ motif was found near the $\mathrm{N}$-terminus which might be important for catalysis (Pechous and Whitaker 2004). Furthermore, all three sequences show an RxR motif implicated in the complexation of the diphosphate function after ionization of the substrate, which prevents nucleophilic attack on any of the carbocationic intermediates formed subsequently (Starks et al. 1997). Analysis of the N-terminus of PSTPS 2 suggested the presence of a 37amino acid plastid transit peptide (http://www.cbs.dtu.dk/ services/ChloroP/) (Emanuelsson et al. 2000). Even though plastid targeting peptides are typical of plant monoterpene synthases (Bohlmann et al. 1998), the PSTPS 2 sequence was most similar to those of sesquiterpene synthases (Fig. 1) when disregarding the putative signal peptide.

In summary, the three $P$. sylvestris cDNAs showed greatest amino acid identity $(60-80 \%)$ to three other conifer sesquiterpene synthases. In comparison with each other, the $P$. sylvestris cDNAs had identities ranging from 60 to $65 \%$, ignoring the signal peptide of PSTPS 2 (Table 2).

Functional expression of $P$. sylvestris sesquiterpene synthases

The three $P$. sylvestris sesquiterpene synthases were heterologously expressed in E. coli, and the crude bacterial extracts containing recombinant protein were incubated with prenyl diphosphates. Product formation was observed for farnesyl diphosphate (FPP), but no terpenoid products were detected after incubation with geranyl diphosphate (GPP) or geranylgeranyl diphosphate (GGPP). Control bacterial extracts containing the empty vector control did not show any enzyme activity. 


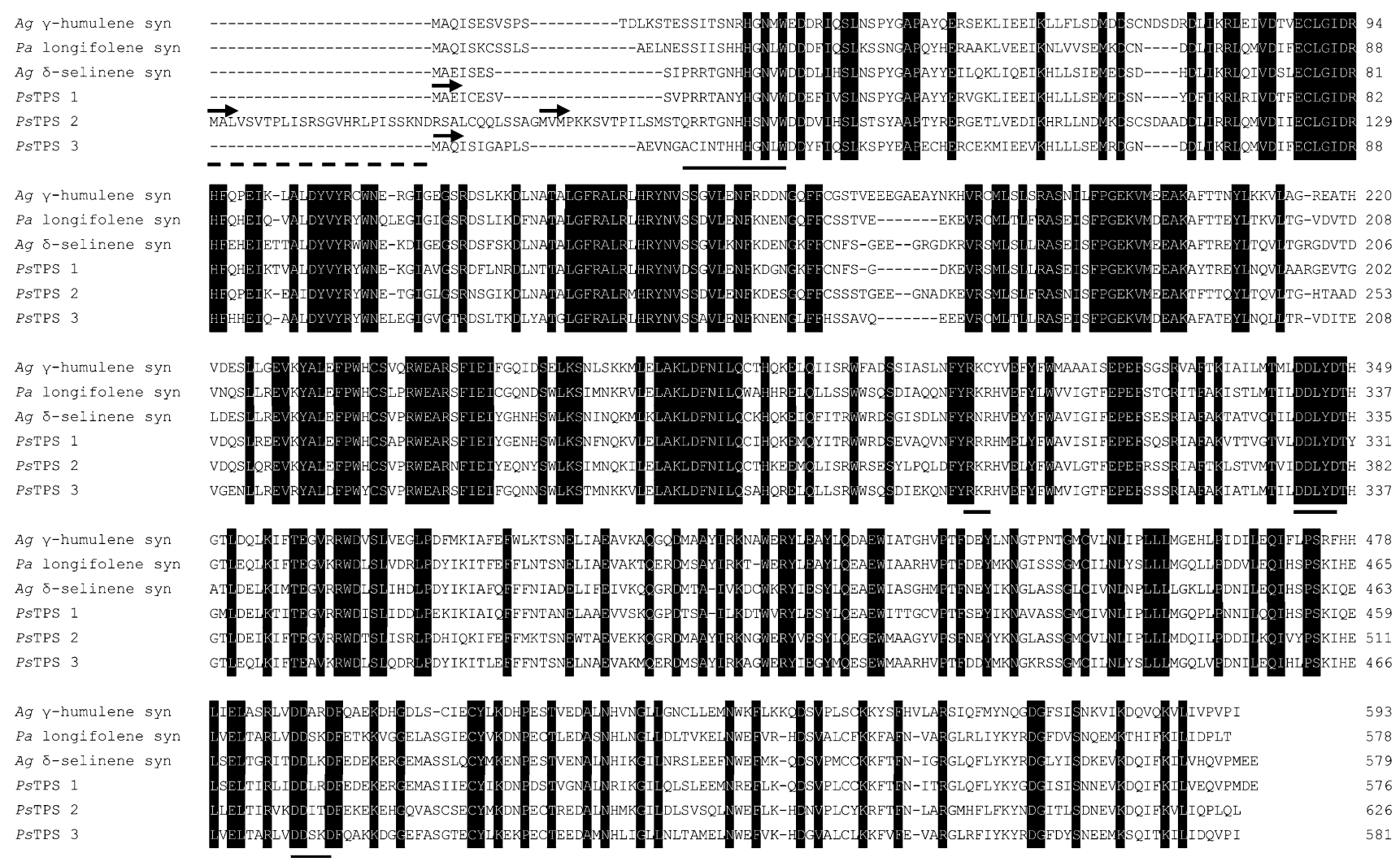

Fig. 1 Alignment of deduced amino acid sequences of three Pinus sylvestris (PS) sesquiterpene synthases, PSTPS 1, PsTPS 2 and PsTPS 3, with the three other conifer sesquiterpene synthases with the highest similarity, Abies grandis ( $\mathrm{Ag}) \gamma$-humulene synthase (GenBank accession AAC05728), $P$. abies $(P a)$ longifolene synthase (GenBank accession AAS47695), A. grandis ( $\mathrm{Ag}) \delta$-selinene synthase (GenBank

accession AAC05727). Amino acid residues that are identical in all six sequences are enclosed in black boxes. The starting codons used for expression are marked with arrows. The DDxxD, RR(x8)W and RxR motifs (solid lines), as well as the ChloroP predicted transit peptide (dotted line) are shown

Table 2 Sequence comparison of $P$. sylvestris and other gymnosperm sesquiterpene synthase sequences

\begin{tabular}{|c|c|c|c|c|c|c|}
\hline PsTPS 1 & 100 & & & & & \\
\hline PsTPS 2 & 64.5 & 100 & & & & \\
\hline PsTPS 3 & 61.9 & 61.2 & 100 & & & \\
\hline$A g \gamma$-humulene syn & 63.9 & 60.6 & 61.9 & 100 & & \\
\hline$P a$ longifolene syn & 63.6 & 65.9 & 79.4 & 64.0 & 100 & \\
\hline \multirow[t]{2}{*}{$A g \delta$-selinene syn } & 77.2 & 65.5 & 64.3 & 62.2 & 63.1 & 100 \\
\hline & PsTPS 1 & PsTPS 2 & PsTPS 3 & $A g \gamma$-humulene syn & $P a$ longifolene syn & $A g \delta$-selinene syn \\
\hline
\end{tabular}

Sequence similarities among PSTPS 1, PSTPS 2 and PSTPS 3, and other conifer sesquiterpene synthases genes, A. grandis $\gamma$-humulene synthase $(A g), P$. abies longifolene synthase $(P a)$, and $A$. grandis $\delta$-selinene synthase $(A g)$ are given in percent at the amino acid level. The analysis was performed using ClustalX and Lasergene 7. The accession numbers of the genes are given in the legend of Fig. 1

PsTPS 1 formed only two main products: $(E)$ - $\beta$-caryophyllene and $\alpha$-humulene, 76.3 and $23.7 \%$, respectively, of total sesquiterpene peak area (Fig. 2a). No other terpenoid products were detectable.

For PsTPS 2, assays were performed with the full ORF and with a construct in which the presumptive 37-amino acid plastid targeting sequence was removed. Both forms gave one major product from FPP, 1(10),5-germacradiene4 -ol $(41.5 \%$ of total sesquiterpene peak area), and two minor products, $\beta$-elemene (19.2\%) and bicyclogermacrene (13.2\%). The detected $\beta$-elemene likely results from the heat-induced rearrangement of germacrene A during gas chromatography (de Kraker et al. 1998). In addition, PsTPS 2 catalyzes the production of some products below $10 \%$ abundance, one of which was tentatively identified by its mass spectrum as $\alpha$-amorphene (Fig. 2b).

PsTPS 3 incubated with FPP produced longifolene as a main product with about $64.2 \%$ of total sesquiterpene peak 
Fig. 2 GC-MS analysis of protein extracts from transformed E. coli expressing $P$. sylvestris terpene synthases. Assay with farnesyl diphosphate. Depicted are total ion current chromatograms in the region of sesquiterpene elution (18-26 min). a PsTPS 1, (1) (E)- $\beta$-caryophyllene, (2) $\alpha$-humulene. b PsTPS 2, (3) $\beta$-elemene, (4) bicyclogermacrene, (5) $\alpha$-amorphene, (6) 1(10),5-germacradiene-4-ol. c PsTPS 3, (7) $\alpha$-longipinene, (8) $\alpha$-ylangene, (9) longicyclene (10) longifolene, and (11) longiborneol. Minor peaks without numbers are unidentified sesquiterpenes or impurities
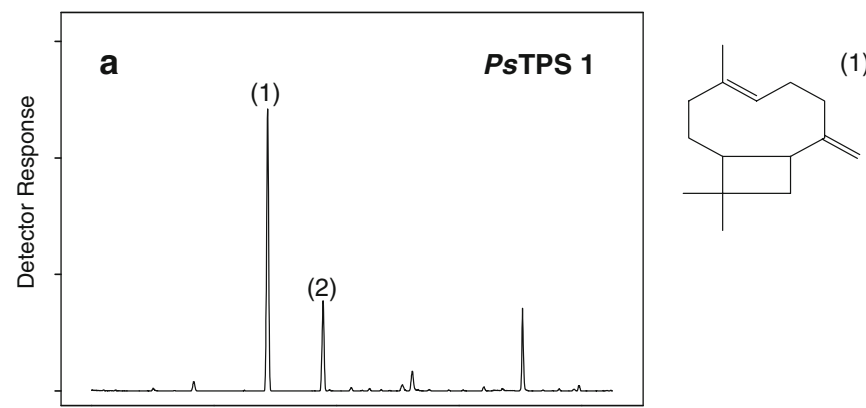<smiles>CCCC(C)=CCCC(C)=CCC(C)(C)C</smiles>

(2)

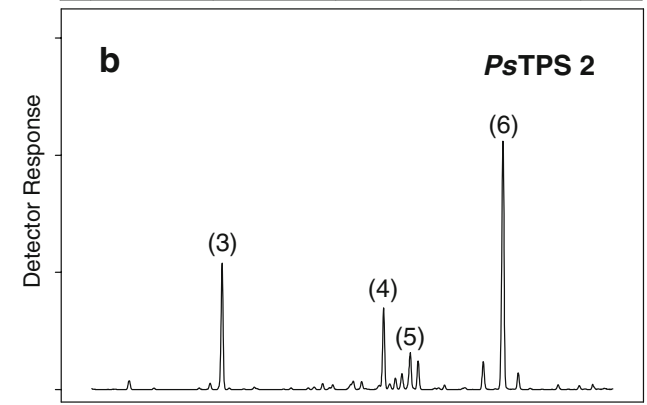<smiles>C=CC1(C)CCC(C(=C)C)CC1C(=C)C</smiles><smiles>CC1=CC2C3=C(CCC2CC1)C(C)(C)C3</smiles><smiles>CC(C)C1/C=C/CCC(C)(O)C(C)CC1</smiles>

PsTPS 3

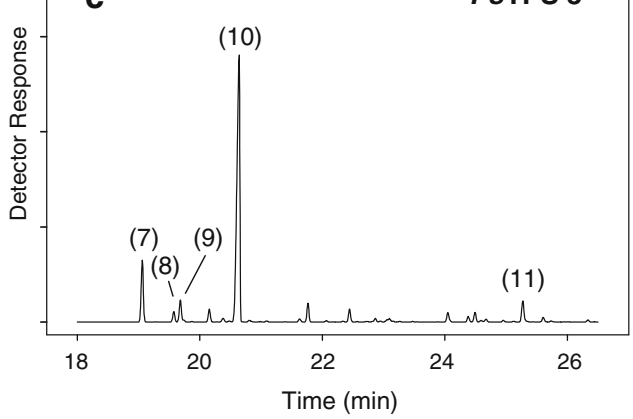<smiles>CC1=CCC2CC1(C)CCC2C(C)C</smiles>

(8)<smiles>CC1=CCC2C3CCCC(C)(C)C3C12</smiles>

(9)

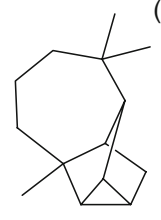

(10)

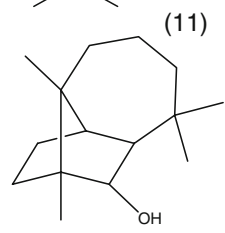

area, $\alpha$-longipinene in smaller amounts (11.2\%), and three minor peaks tentatively identified as $\alpha$-ylangene, longicyclene and longiborneol (Fig. 2c).

None of the three expressed terpene synthases produced (E)- $\beta$-farnesene, the terpene induced by $D$. pini oviposition for which a specific role in egg parasitoid attraction had been documented in previous studies (Mumm et al. 2003; Mumm and Hilker 2005).

The presence of sesquiterpene synthase products in pine needles

Both pine needles $72 \mathrm{~h}$ after egg deposition and the artificially wounded tissue contained the major products of the cloned sesquiterpene synthases: $(E)-\beta$-caryophyllene and $\alpha$-humulene (the main products of recombinant PsTPS 1), $\beta$-elemene, bicyclogermacrene, and 1(10),5-germacradiene-4-ol (the major products of recombinant PsTPS 2), and longifolene (the dominant product of recombinant PsTPS 3). In oviposition-induced pine needles, the main products of PsTPS 1 and PsTPS 2 were slightly more accumulated (1.035 and 1.12 times more) when comparing with artifi- cially wounded control samples (Fig. 3). The content of sesquiterpenes in artificially wounded needles used for calibration were $32 \mu \mathrm{g} / \mathrm{g} \mathrm{FW} \pm 3.2 \beta$-elemene, $54 \mu \mathrm{g} / \mathrm{g} \mathrm{FW} \pm$ $4.8(E)$ - $\beta$-caryophyllene, $9.2 \mu \mathrm{g} / \mathrm{g} \mathrm{FW} \pm 1.1 \alpha$-humulene, $41 \mu \mathrm{g} / \mathrm{g} \mathrm{FW} \pm 5.3$ bicyclogermacrene, and $205 \mu \mathrm{g} / \mathrm{g} \mathrm{FW} \pm$ 16 1(10),5-germacradiene-4-ol. Longifolene was detected only in traces.

The effect of oviposition on sesquiterpene synthase transcript levels

Sawfly oviposition on pine significantly affected transcript levels of PSTPS 1 and PSTPS 2 when compared to artificially wounded pine. In contrast, no such significant treatment (oviposition) effect was detectable for PsTPS 3. Transcript levels of PSTPS 1 and PSTPS 2 also changed significantly over time with a striking increase $72 \mathrm{~h}$ after oviposition. In contrast, no such time effect was found for PSTPS 3 (Fig. 4, Supplemental data Table S2). The results in Table 1 show that odor from $P$. sylvestris twigs was significantly attractive to the egg parasitoid $C$. ruforum only $72 \mathrm{~h}$ after $D$. pini oviposition. At this time, steady state 


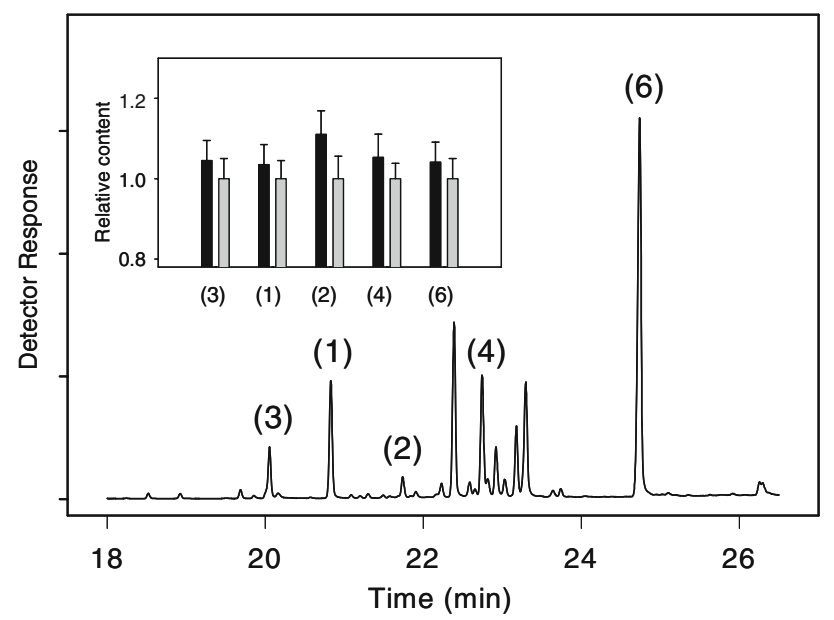

Fig. 3 GC-MS analysis of ether extracts from P. sylvestris needles. Depicted is a total ion current chromatogram from an extract of oviposition-induced pine needles in the region of sesquiterpene elution (18-26 min). For compound numbers see Fig. 2. Inset relative content (means $\pm \mathrm{SE}$ ) of selected sesquiterpenes in oviposition-induced pine needles (black bars) and artificially wounded ones (gray bars) $72 \mathrm{~h}$ after treatment. Data were calibrated against the 72-h-artificiallywounded control. Each value shows the mean of at least three technical replicates of three independent biological samples

transcript levels of PsTPS 1 and PSTPS 2 were on average 1.9 fold and 2.6 fold higher, respectively, than those from non-attractive control twigs $72 \mathrm{~h}$ after artificial wounding (Fig. 4a, b).

\section{Discussion}

We detected three new sesquiterpene synthase genes of $P$. sylvestris and identified the products of the respective enzymes. Furthermore, two of these sesquiterpene synthase genes, PSTPS 1 and PSTPS 2, were significantly upregulated by insect egg deposition, but not by wounding mimicking the ovipositional damage. A number of sesquiterpene synthase genes have been reported from other conifer species including grand fir (A. grandis), Sitka spruce (Picea sitchensis), and Norway spruce (P. abies) (Bohlmann et al. 1999; Martin et al. 2004; Miller et al. 2005; Byun-McKay et al. 2006). The expression of many of these genes is known to be inducible by different factors: mechanical wounding in grand fir (Steele et al. 1998a, b) and Sitka spruce (McKay et al. 2003; Byun-McKay et al. 2006), methyl jasmonate treatment in Sitka spruce (Miller et al. 2005), and insect attack by the stem boring pine weevil (Pissodes strobi) in Sitka spruce (McKay et al. 2003; Miller et al. 2005).

How much do the three new sesquiterpene synthases found in $P$. sylvestris differ from other sesquiterpene synthases in angio- and gymnosperms? The three sesquiter-
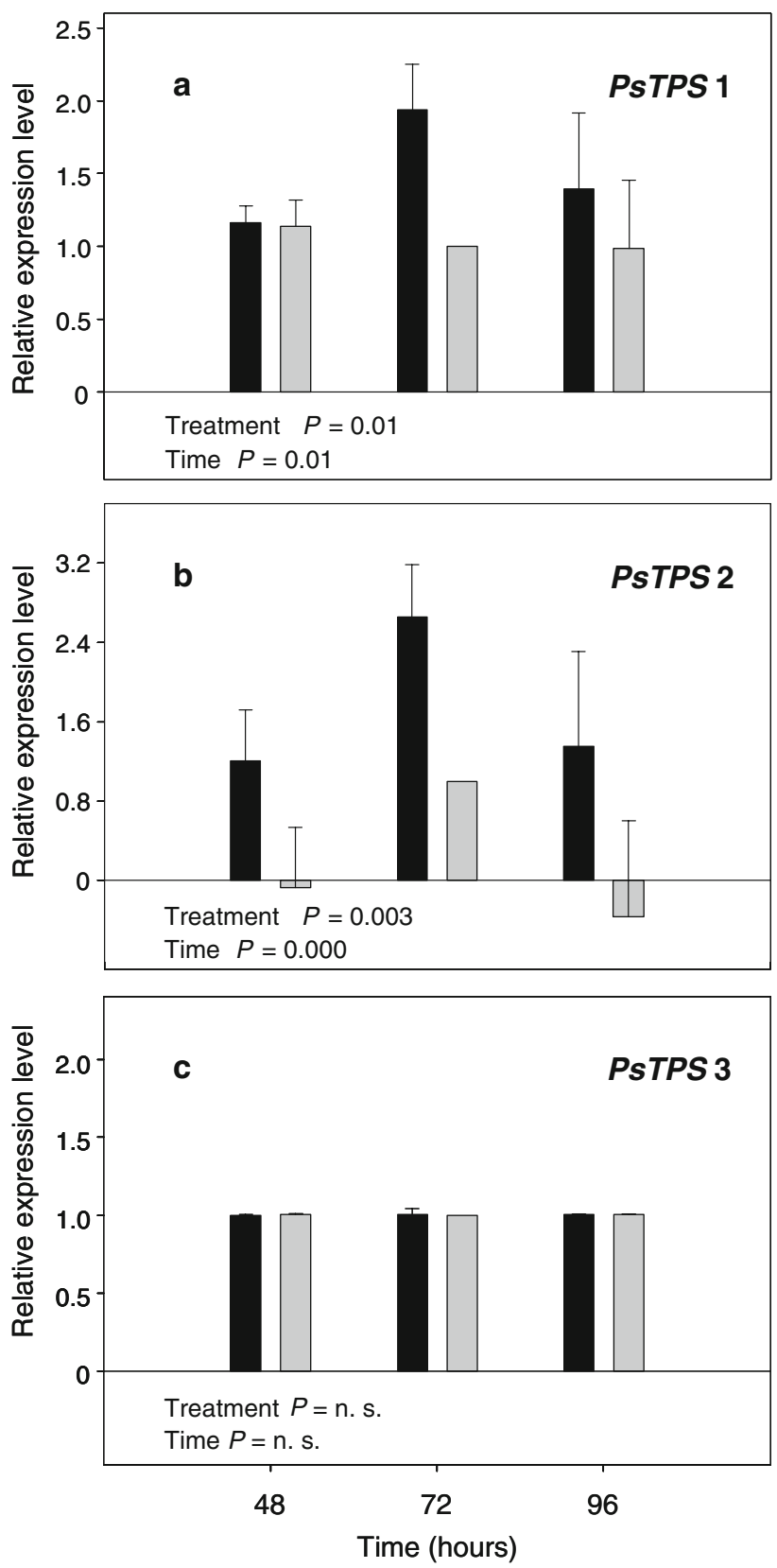

Fig. 4 Relative abundance of mRNA transcripts of genes coding for sesquiterpene synthases of $P$. sylvestris measured by quantitative RTPCR. Transcripts of PSTPS 1 (a), PsTPS 2 (b) and PsTPS 3 (c) were compared in oviposition-induced pine twigs (black bars) and artificially wounded ones (gray bars) 48, 72, and $96 \mathrm{~h}$ after induction (for details see text). Data were normalized to ubiquitin, and calibrated against the $72 \mathrm{~h}$ artificially wounded control (set to 1.0). Each value shows the mean $\pm \mathrm{SE}$ of at least three technical replicates of four (48 h), five (72 h), and three (96 h) independent biological samples. A twoway ANOVA was performed to test the significance of differences in transcript accumulation. n.s., not significant (for details see text and supplemental data S2)

pene synthases isolated from $P$. sylvestris are closely related to those of other gymnosperms. A phylogenetic comparison of these three genes with other selected plant 
terpene synthases resulted in a clear separation of gymnosperm and angiosperm genes (Fig. 5), supporting the suggestion that terpene synthase functions have evolved independently in both groups (Bohlmann et al. 1998; Martin et al. 2004). When considering the sesquiterpene synthases found in P. sylvestris singly, the following similarities and differences compared to sesquiterpene synthases in other plant species are striking:

1. The sequence of the PsTPS 1 enzyme catalyzing the production of $(E)$ - $\beta$-caryophyllene and $\alpha$-humulene have 30 and $27 \%$ amino acid identity to the sequences of $(E)$ - $\beta$-caryophyllene/ $\alpha$-humulene synthases known from Artemisia аппиа (Cai et al. 2002) and A. thaliana (Chen et al. 2003). Of all terpene synthases, PsTPS 1 share $77 \%$ amino acid sequence identity with $A$. grandis $\delta$-selinene synthase (Steele et al. 1998a).

2. The PsTPS 2 enzyme produced 1(10),5-germacradiene-4-ol and other products with a germacrene skeleton. Unexpectedly, the amino acid sequence of this sesquiterpene synthase was found to contain an $\mathrm{N}$-terminal, 37 amino acid signal peptide that may target the protein for plastid localization. However, most sesquiterpene synthases are localized in the cytosol, while monoterpene synthases are usually targeted to plastids
(Keeling and Bohlmann 2006). Nevertheless, a sesquiterpene synthase with a $5^{\prime}$-presequence similar to the one of PsTPS 2 was described previously from another conifer species, Pseudotsuga menziesii (Huber et al. 2005). Without the signal peptide, the PsTPS 2 sequence has highest identity to longifolene synthase isolated from Norway spruce (P. abies) (Martin et al. 2004). Expressing PSTPS 2 without its putative signal sequence gave the same product profile as expressing the full-length ORF.

3. The PSTPS 3 gene encodes a longifolene synthase which has $79 \%$ amino acid identity with a sesquiterpene synthase isolated from Norway spruce ( $P$. abies) (Martin et al. 2004), and a similar product profile. The Norway spruce enzyme also produces longifolene, as well as $\alpha$-longipinene and longiborneol as minor products, as does the PsTPS3 protein.

The transcript levels of the three sesquiterpene synthases studied here are not fully consistent with the profile of volatiles known to be present in the headspace of $P$. sylvestris $72 \mathrm{~h}$ after egg deposition by D. pini (Mumm et al. 2003). Two points are remarkable: first, some of the products of these sesquiterpene synthases, 1(10),5-germacradiene-4-ol (PsTPS2), and longifolene and $\alpha$-longipinene (PsTPS3),

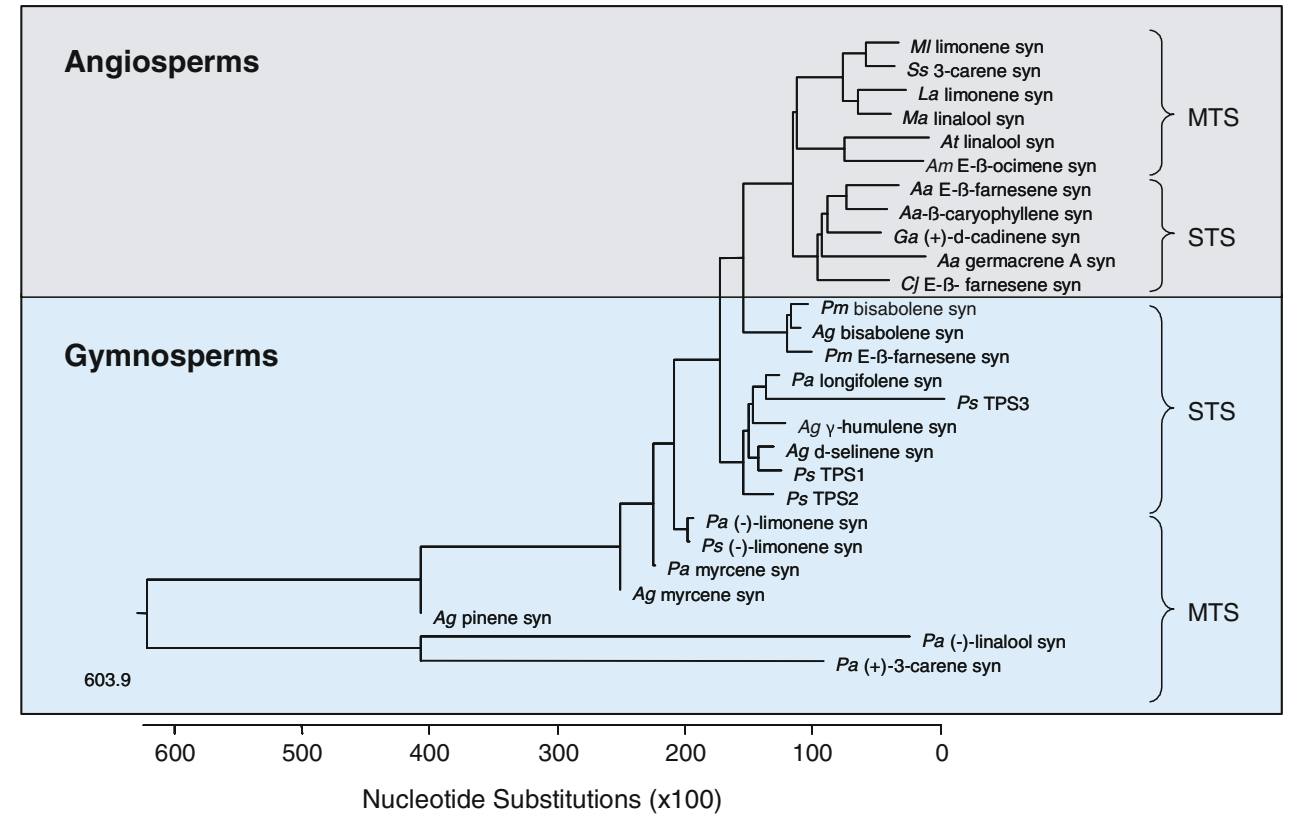

Fig. 5 Phylogenetic tree of the deduced amino acid sequences of PSTPS 1, PSTPS 2 and PSTPS 3 with selected monoterpene synthases $(M T S)$ and sesquiterpene synthases (STS) of angiosperms and gymnosperms calculated by the neighbor-joining method using ClustalW and Lasergene 7 (MegAlign) software. Aa Artemisia annua, Ag Abies grandis, Am Antirrhinum majus, At Arabidopsis thaliana, Cj Citrus junos, Ga Gossypium arboreum, La Lavandula angustifolia, Ma Mentha aquatica, Ml Mentha longifolia, Pa Picea abies, Pm Pseudotsuga menziesii, Ps Pinus sylvestris, Psi Picea sitchensis, Ss Salvia stenophylla. GenBank protein accessions of terpene synthases are shown top to bottom: AAD50304, AAM89254, ABB73044, AAL99381, AAO85533, AAO42614, AAX39387, AAL79181, ABE3980, AAD51718, AAK54279, AAX07266, AAC24192, AAX07265, AAS47695, AAC05728, AAC05727, AAS47694, ABA86248, AAS47696, AAB71084, AAB71085, AAS47693, AAO73863 
have not yet been detected in the headspace of ovipositioninduced pine (Mumm et al. 2003). Second, even though PsTPS 1 and PsTPS 2 increase their transcript levels significantly $72 \mathrm{~h}$ after egg deposition with respect to earlier time points and artificially wounded controls, none of their products was found in enhanced quantities in the headspace of oviposition-induced pine when compared to artificially wounded samples (Mumm et al. 2003). Thus, the steady state transcript levels found for PsTPS 1 and PsTPS 2 are not reflected by enhanced quantities of their products in the headspace of oviposition-induced pine.

How can these inconsistencies be explained? While both 1(10),5-germacradiene-4-ol and longifolene were not detected in the headspace of oviposition-induced pine in previous work (Mumm et al. 2003), we did find these components in total needle extracts (Fig. 3). The absence of the major products of PsTPS 2 and 3 in previous headspace collections might result from these compounds being below the detection limit for the methods used (Mumm et al. 2003). However, the major products of PsTPS 1, (E)- $\beta$ caryophyllene and $\alpha$-humulene, were indeed found in the headspace of pine $72 \mathrm{~h}$ after sawfly egg deposition, but not in enhanced quantities compared to artificially wounded pine (Mumm et al. 2003). The formation of these sesquiterpenes may not be strictly controlled at the transcript level of their respective sesquiterpene synthases. A variety of posttranscriptional controls, including gene silencing or RNA interference (Bonnet et al. 2006; Poethig et al. 2006) or controls on enzyme activity may be in operation. Alternatively, the products of PsTPS 1 and PsTPS 2 may be biosynthesized in higher quantities in oviposition-induced needles than in artificially wounded ones consistent with their enhanced transcription levels, but might remain in the egg-laden needles rather than being volatilized and serve as direct defenses against the eggs or larvae of the sawfly. Our quantitative analyses of sesquiterpenes in ovipositioninduced needles indicate indeed slight accumulation of the major products of PsTPS 1 and PsTPS 2 (Fig. 3). The question of whether the products of the cloned sesquiterpene synthases have noxious or deterrent direct effects on $D$. pini eggs needs to be addressed in future work. Further molecular studies will also search for an $(E)$ - $\beta$-farnesene synthase. This sesquiterpene is so far the only terpenoid volatile component found in significantly enhanced quantities $72 \mathrm{~h}$ after sawfly egg deposition (Mumm et al. 2003).

In conclusion, this study provides molecular evidence that insect egg deposition by $D$. pini triggers enhanced transcription of sesquiterpene synthases in $P$. sylvestris. This transcriptional response was shown to be induced specifically by egg deposition, but not by artificial damage. The enhanced transcription was observed only at that time after egg deposition $(72 \mathrm{~h})$ when the egg-laden pine released odor attractive to the parasitoid.
Acknowledgments Many thanks are due to Ute Braun and Ivo Beyaert, Freie Universität Berlin, for rearing the insects and helping to prepare the pine twig treatments. Moreover, we thank Marion Stäger, Max Planck Institute for Chemical Ecology, Jena, for technical assistance. The study was supported by the Deutsche Forschungsgemeinschaft (DFG Schm 2150/2-1 and DFG Hi 416/17-1) and the Max Planck Society.

Open Access This article is distributed under the terms of the Creative Commons Attribution Noncommercial License which permits any noncommercial use, distribution, and reproduction in any medium, provided the original author(s) and source are credited.

\section{References}

Arimura G, Huber DPW, Bohlmann J (2004) Forest tent caterpillars (Malacosoma disstria) induce local and systemic diurnal emissions of terpenoid volatiles in hybrid poplar (Populus trichocarpa $\times$ deltoides): cDNA cloning, functional characterization, and patterns of gene expression of (-)-germacrene D synthase, PtdTPS1. Plant J 37:603-616

Bohlmann J, Meyer-Gauen G, Croteau R (1998) Plant terpenoid synthases: molecular biology and phylogenetic analysis. Proc Natl Acad Sci USA 95:4126-4133

Bohlmann J, Phillips M, Ramachandiran V, Katoh S, Croteau R (1999) cDNA Cloning, characterization, and functional expression of four new monoterpene synthase members of the Tpsd gene family from grand fir (Abies grandis). Arch Biochem Biophys 368:232243

Bombosch S, Ramakers PMJ (1976) Zur Dauerzucht von Gilpinia hercyniae. Pflanzenkrankheiten und Pflanzenschutz 83:40-44

Bonnet E, van de Peer Y, Rouzé P (2006) The small RNA world of plants. New Phytol 171:451-468

Bradford MM (1976) A rapid and sensitive method for the quantitation of microgram quantities of protein utilizing the principle of protein-dye binding. Anal Biochem 72:248-254

Byun-McKay A, Godard KA, Toudefallah M, Martin DM, Alfaro R, King J, Bohlmann J, Plant AL (2006) Wound-induced terpene synthase gene expression in Sitka spruce that exhibits resistance or susceptibility to attack by the white pine weevil. Plant Physiol 140:1009-1021

Cai Y, Jia JW, Crock J, Lin ZX, Chen XY, Croteau R (2002) A cDNA clone for beta-caryophyllene synthase from Artemisia annua. Phytochemistry 61:523-529

Chen F, Tholl D, d'Auria JC, Farooq A, Pichersky E, Gershenzon J (2003) Biosynthesis and emission of terpenoid volatiles from Arabidopsis flowers. Plant Cell 15:1-14

Colazza S, Fucarino A, Peri E, Salerno G, Conti E, Bin F (2004) Insect oviposition induces volatile emission in herbaceous plants that attracts egg parasitoids. J Exp Biol 207:47-53

de Kraker JW, Franssen MCR, de Groot A, König WA, Bouwmeester HJ (1998) (+)-Germacrene A biosynthesis: the committed step in the biosynthesis of sesquiterpene lactones in chicory. Plant Physiol 117:1381-1392

Dicke M, van Loon JJA (2000) Multitrophic effects of herbivore-induced plant volatiles in an evolutionary context. Entomol Exp Appl 97:237-249

Emanuelsson O, Nielsen H, Brunak H, von Heijne G (2000) Predicting subcellular localization of proteins based on their $\mathrm{N}$-terminal amino acid sequence. J Mol Biol 300:1005-1016

Eichhorn O, Pschorn-Walcher H (1976) Studies on biology and ecology of egg parasites (Hym-Chalcidoidea) of pine sawfly Diprion pini (L.) (Hym-Diprionidae) in Central Europe. Z Angew Entomol 80:355-381 
Gatehouse JA (2002) Plant resistance towards insect herbivores: a dynamic interaction. New Physiol 156:145-169

Hilker M, Kobs C, Varma Schrank K (2002a) Insect egg deposition induces Pinus sylvestris to attract egg parasitoids. J Exp Biol 205:455-461

Hilker M, Meiners T (2002) Induction of plant responses to oviposition and feeding by herbivorous arthropods: a comparison. Entomol Exp Appl 104:181-192

Hilker M, Meiners T (2006) Early herbivore alert: insect eggs induce plant defense. J Chem Ecol 32:1379-1397

Hilker M, Rohfritsch O, Meiners T (2002b) The plant's response towards insect egg deposition. In: Hilker M, Meiners $\mathrm{T}$ (eds) Chemoecology of insect eggs and egg deposition. Blackwell, Berlin, pp 205-234

Hilker M, Stein C, Schröder R, Varama M, Mumm R (2005) Insect egg deposition induces defence responses in Pinus sylvestris: characterisation of the elicitor. J Exp Biol 208:1849-1854

Huber DPW, Philippe RN, Godard KA, Sturrock RN, Bohlmann J (2005) Characterization of four terpene synthase cDNAs from methyl jasmonate-induced Douglas-fir, Pseudotsuga menziesii. Phytochemistry 66:1427-1439

Kappers IF, Aharoni A, van Herpen T, Luckerhoff LLP, Dicke M, Bouwmeester HJ (2005) Genetic engineering of terpenoid metabolism attracts bodyguards to Arabidopsis. Science 309:2070-2072

Karban R, Baldwin IT (1997) Induced responses to herbivory. The University of Chicago Press, Chicago

Keeling CI, Bohlmann J (2006) Genes, enzymes and chemicals of terpenoid diversity in the constitutive and induced defence of conifers against insects and pathogens. New Phytol 170:657-675

Köhler W, Schachtel G, Voleske P (1995) Biostatistik. Springer, Berlin

Little D, Gouhier-Darimont C, Bruessow F, Reymond P (2007) Oviposition by pierid butterflies triggers defence responses in Arabidopsis. Plant Physiol 143:784-800

Martin D, Tholl D, Gershenzon J, Bohlmann J (2002) Methyl jasmonate induces traumatic resin ducts, terpenoid resin biosynthesis, and terpenoid accumulation in developing xylem of Norway spruce stems. Plant Physiol 129:1003-1018

Martin DM, Fäldt J, Bohlmann J (2004) Functional characterization of nine Norway spruce TPS genes and evolution of gymnosperm terpene synthases of the TPS- $d$ subfamily. Plant Physiol 135:19081927

McKay SAB, Hunter WL, Godard KA, Wang SX, Martin DM, Bohlmann J, Plant AL (2003) Insect attack and wounding induce traumatic resin duct development and gene expression of (-)-pinene synthase in Sitka spruce. Plant Physiol 133:368-378

Meiners T, Hilker M (2000) Induction of plant synomones by oviposition of a phytophagous insect. J Chem Ecol 26:221-232

Miller B, Madilao LL, Ralph S, Bohlmann J (2005) Insect-induced conifer defense. White pine weevil and methyl jasmonate induce traumatic resinosis, de novo formed volatile emissions, and accumulation of terpenoid synthase and putative octadecanoid pathway transcripts in Sitka spruce. Plant Physiol 137:369-382

Moore GE, Clark EW (1968) Suppressing microorganisms and maintaining turgidity in coniferous foliage used to rear insects in laboratory. J Econ Entomol 61:1030-1031
Mumm R, Hilker M (2005) The significance of background odour for an egg parasitoid to detect plants with host eggs. Chem Senses 30:337-343

Mumm R, Hilker M (2006) Direct and indirect chemical defence of pine against folivorous insects. Trends Plant Sci 11:351-358

Mumm R, Schrank K, Wegener R, Schulz S, Hilker M (2003) Chemical analysis of volatiles emitted by Pinus sylvestris after induction by insect oviposition. J Chem Ecol 29:1235-1252

Mumm R, Tiemann T, Varama M, Hilker M (2005) Choosy egg parasitoids: specificity of oviposition-induced pine volatiles exploited by an egg parasitoid of pine sawflies. Entomol Exp Appl $115: 217-225$

Paré PW, Tumlinson JH (1997) Induced synthesis of plant volatiles. Nature 385:30-31

Pechous SW, Whitaker BD (2004) Cloning and functional expression of an (E, E)-alpha-farnesene synthase cDNA from peel tissue of apple fruit. Planta 219:84-94

Poethig RS, Peragine A, Yoshikawa M, Hunter C, Willmann M, Wu G (2006) The function of RNAi in plant development. Cold Spring Harb Symp Quant Biol 71:165-170

Pettersson J (1970) An aphid sex attractant I. Biological studies. Entomol Scand 1:63-73

Röse USR, Manukian A, Heath RR, Tumlinson JH (1996) Volatile semiochemicals released from undamaged cotton leaves-a systemic response of living plants to caterpillar damage. Plant Physiol 111:487-495

Röse USR, Tumlinson JH (2004) Volatiles released from cotton plants in response to Helicoverpa zea feeding damage on cotton flower buds. Planta 218:824-832

Schnee C, Köllner TG, Held M, Turlings TCJ, Gershenzon J, Degenhardt J (2006) The products of a single maize sesquiterpene synthase form a volatile defense signal that attracts natural enemies of maize herbivores. Proc Natl Acad Sci USA 103:1129-1134

Starks CM, Back K, Chappell J, Noel JP (1997) Structural basis for cyclic terpene biosynthesis by tobacco 5 -epi-aristolochene synthase. Science 277:1815-1820

Steele CL, Crock J, Bohlmann J, Croteau R (1998a) Sesquiterpene synthases from grand fir (Abies grandis) — comparison of constitutive and wound-induced activities, and cDNA isolation, characterization and bacterial expression of delta-selinene synthase and gamma-humulene synthase. J Biol Chem 273:2078-2089

Steele CL, Katoh S, Bohlmann J, Croteau R (1998b) Regulation of oleoresinosis in grand fir (Abies grandis) - differential transcriptional control of monoterpene, sesquiterpene, and diterpene synthase genes in response to wounding. Plant Physiol 116:14971504

Sokal RR, Rohlf FJ (1995) Introduction to biostatistics, 2nd edn. Freeman and Co., New York

Van Poecke RMP, Dicke M (2004) Indirect defence of plants against herbivores: using Arabidopsis thaliana as a model plant. Plant Biol 6:387-401

Vet LEM, van Lenteren JC, Heymans M, Meelis E (1983) An airflow olfactometer for measuring olfactory responses of hymenopterous parasitoids and other small insects. Physiol Entomol 8:97-106

Walling L (2000) The myriad plant responses to herbivores. J Plant Growth Regul 19:195-216 